\title{
A Velocity-Based Seismic Control for Base-Isolated Building Structures
}

\author{
Francesc Pozo, Leonardo Acho, José Rodellar and Josep Maria Rossell
}

\begin{abstract}
Passive, active and semi-active control have been extensively considered to improve the protection of base-isolated structures against earthquakes. This paper presents a strategy to apply control forces to the base of an isolated structure to enhance the performance of purely passive devices. The main feature is the simplicity in formulation, design and implementation. It is formulated as a static nonlinear function depending only on the base velocity. This function ensures energy dissipation capability with always bounded control force. The control is applied to a three-dimensional benchmark problem which is used by the structural control community as a state-of-the-art model for numerical experiments of seismic control attenuation. Several performance indices show that the proposed controller is efficient with a reasonable control effort.
\end{abstract}

\section{INTRODUCTION}

Base isolation has been widely considered as an effective technology to protect flexible structures up to eight storeys high against earthquakes. The conceptual objective of the isolator is to produce a dynamic decoupling of the structure from its foundation so that the structure ideally behaves like a rigid body with reduced inter-story drifts, as demanded by safety, and reduced absolute accelerations as related to comfort requirements. Although the response variables of a base-isolated building are reduced substantially in comparison with the fixed-base case, the base displacement may be excessive, particularly during near-field ground motions [8]. In this sense, the combination of passive base isolators and feedback controllers (applying forces to the base) has been proposed in recent years. Some researchers have proposed active feedback systems, for instance [1], [9], [10], [17]. More recently, semiactive controllers have been proposed in the same setting with the hope of gaining advantage from their easier implementation (see for instance [2], [11], [12], [19]). It is accepted that passive, semi-active and active control systems installed in parallel with base-isolation bearings have the potential of reducing responses of baseisolated structures more significantly than classical passive dampers [8], [19]. Consequently, it is still an open issue the research to design alternative protective systems for baseisolated structures.

F. Pozo and L. Acho are with CoDAlab, Departament de Matemàtica Aplicada III, Escola Universitària d'Enginyeria Tècnica Industrial de Barcelona (EUETIB), Universitat Politècnica de Catalunya (UPC), Comte d'Urgell, 187, 08036 Barcelona, Spain francesc.pozo@upc.edu, leonardo. acho@upc. edu

J. Rodellar is with CoDAlab, Departament de Matemàtica Aplicada III, Escola Tècnica Superior d'Enginyers de Camins, Canals i Ports de Barcelona (ETSECCPB), Universitat Politècnica de Catalunya (UPC), Jordi Girona, 1-3, 08034 Barcelona, Spain jose.rodellar@upc.edu

J. M. Rossell is with CoDAlab, Departament de Matemàtica Aplicada III, Escola Politècnica Superior d'Enginyeria de Manresa (EPSEM), Universitat Politècnica de Catalunya (UPC), Av. Bases de Manresa, 61-73, 08240 Manresa, Spain josep.maria.rossell@upc.edu
In this context, a benchmark structural control model for building structures was developed by the American Society of Civil Engineering (ASCE) Committee on Structural Control to provide systematic and standardized means by which competing control strategies -including devices, algorithms, sensors, etc.- can be evaluated [13], [14], [15]. Moreover, analytical benchmark problems are an excellent alternative to expensive experimental benchmark test structures.

In this paper, a new controller is presented. The main motivating factor is to ensure a damping capability with a simple and bounded control law. The damping feature is achieved by using a passive function depending on the velocity. This also keeps the simplicity in the implementation, since requires a single local response variable. Simplicity in the formulation and boundedness are ensured by proposing a static hyperbolic function. The paper has two main parts. The first one presents conceptually the design and basic properties of the control law to be applied to the base of an isolated structure. In the second part, the performance of the proposed controller, for seismic attenuation, is evaluated by numerical simulations using the smart base-isolated benchmark building [13], [14], [15].

\section{CONTROL DESIGN}

\section{A. System description}

Consider a nonlinear base-isolated building structure as shown in Figure 1. For control design and because the mathematical model of the benchmark structure is very complicated and cannot be used directly for control purposes, a dynamic model composed of two coupled subsystems, namely, the main structure or superstructure $\left(S_{r}\right)$ and the base isolation $\left(S_{c}\right)$ [18], is employed:

$$
\begin{aligned}
S_{r}: & \mathbf{M} \ddot{\mathbf{x}}=-\mathbf{M J} \ddot{x}_{g}+\mathbf{C} \dot{\mathbf{r}}+\mathbf{K r} \\
S_{c}: & m_{0} \ddot{x}_{0}+c_{0} \dot{x}_{0}+k_{0} x_{0}= \\
& c_{1} \dot{r}_{1}+k_{1} r_{1}-\Phi\left(x_{0}, t\right)-m_{0} \ddot{x}_{g}+u
\end{aligned}
$$

where $\ddot{x}_{g}$ is the absolute ground acceleration, $\mathbf{x}=$ $\left[x_{1}, x_{2}, \ldots, x_{8}\right]^{\mathrm{T}} \in \mathbb{R}^{8}$ represents the horizontal displacements of each floor with respect to the ground. The mass, damping and stiffness of the $i$ th storey is denoted by $m_{i}, c_{i}$ and $k_{i}$, respectively, $\mathbf{r}=\left[r_{1}, \ldots, r_{8}\right]^{\mathrm{T}} \in \mathbb{R}^{8}$, represents the horizontal displacements of the $i$-th floor relative to the $(i-1)$-th storey. The base isolation is described as a single degree of freedom with horizontal displacement $x_{0}$. It is assumed to exhibit a linear behavior characterized by mass, damping and stiffness $m_{0}, c_{0}$ and $k_{0}$, respectively, plus a nonlinear behavior represented by a hysteretic restoring force 
$\Phi\left(x_{0}, t\right)$. The matrices $\mathbf{M}, \mathbf{C}, \mathbf{K}$ and $\mathbf{J}$ of the structure have the following form

$$
\begin{gathered}
\mathbf{M}=\operatorname{diag}\left(m_{1}, m_{2}, \ldots, m_{8}\right) \in \mathbb{R}^{8 \times 8} \\
\mathbf{J}=[1, \ldots, 1]^{\mathrm{T}} \in \mathbb{R}^{8} \\
\mathbf{C}=\left(c_{i j}\right) \in \mathbb{R}^{8 \times 8}, c_{i j}= \begin{cases}-c_{i}, & i=j \\
c_{i+1}, & j-i=1 \\
0, & \text { otherwise }\end{cases} \\
\mathbf{K}=\left(k_{i j}\right) \in \mathbb{R}^{8 \times 8}, k_{i j}= \begin{cases}-k_{i}, & i=j \\
k_{i+1}, & j-i=1 \\
0, & \text { otherwise }\end{cases}
\end{gathered}
$$

For the restoring force $\Phi$, it is considered the existence of seismic isolators described by the Bouc-Wen model [5], [6], [7] in the following form:

$$
\begin{aligned}
\Phi\left(x_{0}, t\right) & =\alpha K x_{0}(t)+(1-\alpha) D K z(t) \\
\dot{z} & =D^{-1}\left(A \dot{x}_{0}-\beta\left|\dot{x}_{0}\right||\dot{z}|^{n-1} z-\lambda \dot{x}_{0}|z|^{n}\right)
\end{aligned}
$$

where $\Phi\left(x_{0}, t\right)$ can be considered as the superposition of an elastic component $\alpha K x$ and a hysteretic component $(1-\alpha) D K z(t)$, in which the yield constant displacement is $D>0$ and $\alpha \in(0,1)$ is the post- to pre-yielding stiffness ratio. $n \geq 1$ is a scalar that governs the smoothness of the transition from elastic to plastic response and $K>0$. Finally, $u$ is the control force supplied by an appropriate actuator.

The model in (1)-(2) is used to design an appropriate control law. The applicability and efficiency of the proposed controller will be then shown using a more realistic and complex model through the benchmark presented in Section III.

The equation of motion of the base (2) can be rewritten in the form

$$
\begin{aligned}
S_{c}: & m_{0} \ddot{x}_{0}+c_{0} \dot{x}_{0}+k_{0} x_{0}= \\
& \underbrace{c_{1}\left(\dot{x}_{1}-\dot{x}_{0}\right)+k_{1}\left(x_{1}-x_{0}\right)}_{\delta\left[x_{0}, \dot{x}_{0}, x_{1}, \dot{x}_{1}\right]} \underbrace{-\Phi\left(x_{0}, t\right)-m_{0} \ddot{x}_{g}}_{\Delta(t)}+u .
\end{aligned}
$$

It is well accepted that the movement of the superstructure $S_{r}$ is very close to the one of a rigid body due to the base isolation [20]. Then it is reasonable to assume that the motion of the first floor relative to the base will be very small. Therefore, it is also reasonable to consider that the interaction force $\delta\left[x_{0}, \dot{x}_{0}, x_{1}, \dot{x}_{1}\right]$ will be small in comparison with the rest of the forces acting on the base [12], [18]. Consequently, the following simplified equation of motion of the base can be used in the subsequent controller design:

$$
\tilde{S}_{c}: m_{0} \ddot{x}_{0}+c_{0} \dot{x}_{0}+k_{0} x_{0}=-\Phi\left(x_{0}, t\right)-m_{0} \ddot{x}_{g}+u \text {. }
$$

The feasibility of this simplification will be justified in a more detailed way in Section IV from the results of the application of the control to the benchmark structure.

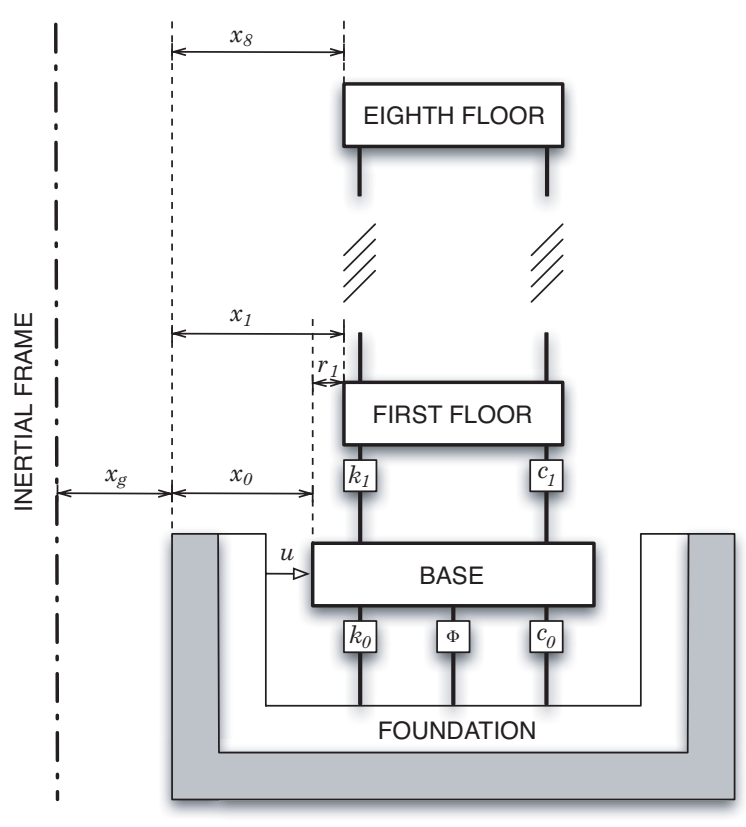

Fig. 1. Base-isolated structure with active control.

\section{B. Hyperbolic control}

1) Control objective and design: We seek for a controller exhibiting the following features:

(a) To be a static controller employing only local velocity information between the two points where the controller is connected.

(b) To be an admissible controller, that is, when the seismic excitation is not present $\left(\ddot{x}_{g}=0\right)$, the closed-loop system is asymptotically stable.

(c) Ensure that, when the seismic excitation is present, all the trajectories of the closed-loop system are bounded.

Consider a passive function $g: \mathbb{R} \mapsto \mathbb{R}, g \in \mathcal{C}^{1}$, that is, a function such that $g(x) \cdot x \geq 0, g(0)=0$. Then we propose a control law with the following structure:

$$
u=-\rho \cdot g(\dot{x})
$$

where $\rho>0$ is a coefficient, and $\dot{x}$ the local velocity between the two points where the controller is connected.

Clearly, when $g(\dot{x})=\operatorname{sgn}(\dot{x})$, the signum function, the resulting controller is equivalent to the well-known pure friction damper. When $g(\dot{x})=\dot{x}$, the controller is the classical local proportional velocity control equivalent to a linear damper.

In this work, a different passive function is proposed with the following hyperbolic form:

$$
g(\dot{x})=\operatorname{sech}\left(\frac{\dot{x}}{a}\right) \cdot \tanh \left(\frac{\dot{x}}{a}\right),
$$

where $a>0$ is a design parameter.

Figure 2 plots this function and may help to highlight some nice features in relation to the control objective: 
- The value of $g(\dot{x})$ is bounded irrespective of the value of the velocity $\dot{x}$. The maximum control input is prescribed by choosing the gain parameter $\rho$. This boundedness will be a key point later on to ensure the desired stability of the closed loop.

- The maximum absolute value of $g$ is reached for the velocities $\dot{x}= \pm \bar{a}= \pm a \cdot \operatorname{arctanh}(\sqrt{2} / 2)$. This means that the design parameter $a$ can be easily selected to prescribe these velocities. For velocities within the range $\dot{x} \in[-\bar{a}, \bar{a}]$, the response of the controller is like the one of a typical s-shaped nonlinear damper. For velocities beyond this range, the control force smoothly decays. In practice, the value of $a$ can be designed large enough to prescribe an always bounded control force with a certain damping profile within a range of the maximum expected velocities.

The following assumption is stated now for system (3)-(5): Assumption 1: The earthquake disturbance

$$
f(t)=-m_{0} \ddot{x}_{g}(t)
$$

is unknown but bounded; i.e., there exists a known constant $F$ such that $|f(t)| \leq F, \quad \forall t \geq 0$.

Moreover, Theorem 1 in [5] guarantees the existence of a computable upper bound $\bar{\rho}_{z}$ on the internal dynamic variable $z(t)$, i.e., $|z(t)| \leq \bar{\rho}_{z}, \forall t \geq 0$, independently on the boundedness of $x_{0}(t)$.

The following Theorem ends the controller design.

Theorem 1: Consider the nonlinear system (3)-(5) subject to Assumption 1. Then, the following control law

$$
\begin{aligned}
u & =-\rho \cdot g\left(\dot{x}_{0}\right) \\
& =-\rho \cdot \operatorname{sech}\left(\frac{\dot{x}_{0}}{a}\right) \cdot \tanh \left(\frac{\dot{x}_{0}}{a}\right)
\end{aligned}
$$

where $a>0$ and $\rho>0$ are design parameters, solves the control objective.

\section{SMART BASE-ISOLATED BENCHMARK BUILDING}

The smart base-isolated benchmark building [13] is employed as an interesting and more realistic example to further investigate the effectiveness of the proposed design approach. This benchmark problem is recognized by the American Society of Civil Engineers (ASCE) Structural Control Committee as a state-of-the-art model developed to provide a computational platform for numerical experiments of seismic control attenuation [16].

The benchmark structure is an eight-storey frame building with steel-braces, $82.4 \mathrm{~m}$ long and $54.3 \mathrm{~m}$ wide, similar to existing buildings in Los Angeles, California. Stories one to six have an L-shaped plan while the higher floors have a rectangular plan. The superstructure rests on a rigid concrete base, which is isolated from the ground by an isolator layer, and consists of linear beam, column and bracing elements and rigid slabs. Below the base, the isolation layer consists of a variety of 92 isolation bearings. The isolators are connected between the drop panels and the footings below, as shown in Figure 3.

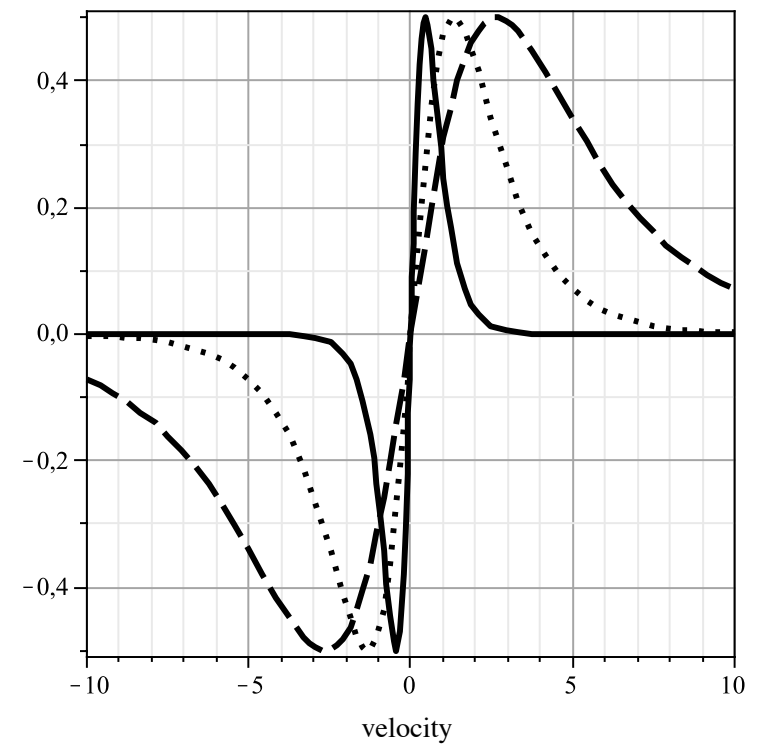

Fig. 2. Hyperbolic passive function (7) with $a=0.5, a=1.5$ and $a=3$. The maximum absolute value is obtained for the velocities $\pm a$. $\operatorname{arctanh}(\sqrt{2} / 2)$.

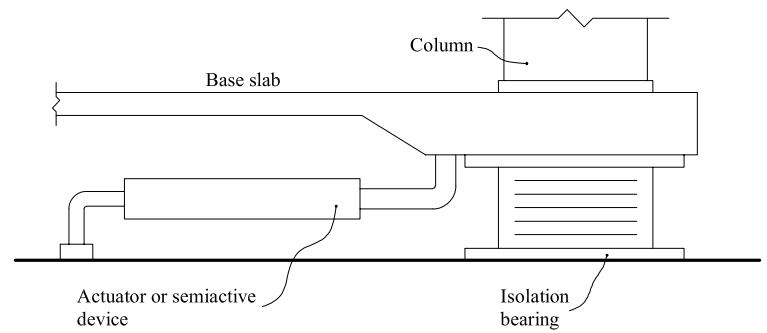

Fig. 3. Elevation view with devices.

\section{NUMERICAL RESULTS}

The results of the hyperbolic control in equation (7) of the benchmark problem are summarized in Table I, for the fault normal (FN) component and the fault parallel (FP) components acting in two perpendicular directions. The results are also compared with the performance indices in [3]. The evaluation is reported in terms of the performance indices described in [13] or in [18]. The controlled benchmark structure is simulated for seven earthquake ground accelerations defined in the benchmark problem (Newhall, Sylmar, El Centro, Rinaldi, Kobe, Ji-Ji and Erzinkan). All the excitations are used at the full intensity for the evaluation of the performance indices. The performance indices larger than 1 indicate that the response of the controlled structure is bigger than that of the uncontrolled structure. These quantities are highlighted in bold.

In this paper, the controllers are assumed to be fully active. They are placed in eight specific locations, including the corners and center of mass of the base. At each location, there are two controllers -one in the $x$ - and the other in the $y$ direction. These actuators are used to apply the active control 
forces to the base of the structure. In this control strategy most of the response quantities are reduced substantially from the uncontrolled cases.

The base and structural shears are reduced between 21 and $50 \%$ in a majority of earthquakes (except El Centro and Ji-ji). The reduction in base displacement is between 7 and $45 \%$ in all cases except Ji-ji. Reductions in the inter-storey drifts between 14 and $48 \%$ are achieved in a majority of earthquakes (except Ji-ji) when compared to the uncontrolled case. The floor accelerations are also reduced by $14-46 \%$ in a majority of earthquakes (except Rinaldi and Ji-ji).

The benefit of the active control strategy is the reduction of base displacements $\left(J_{3}\right)$ and shears $\left(J_{1}, J_{2}\right)$ of up to $50 \%$ without increase in drift $\left(J_{4}\right)$ or accelerations $\left(J_{5}\right)$. The reduction of the peak base displacement $J_{3}$ of the baseisolated building is one of the most important criteria during strong earthquakes.

For the base-isolated buildings, superstructure drifts are reduced significantly compared to the corresponding fixedbuildings because of the isolation from the ground motion. Hence, a controller that reduces or does not increase the peak superstructure drift $\left(J_{4}\right)$, while reducing the base displacement significantly $\left(J_{3}\right)$, is desirable for practical applications [21]. In this respect, the proposed hyperbolic controller performs well.

\section{Time-history plots}

Figures 5-7 show the time-history plots of various response quantities for the uncontrolled building, and the building with hyperbolic controllers using the Erzinkan FP- $x$, FN- $y$ earthquake. Figure 4 shows the ground acceleration for this earthquake. More precisely, Figure 5 presents the plots for the displacement of the center of the mass of the base in both the $x$ and $y$ direction. The plotted quantities in Figure 6 are the eighth floor absolute acceleration in the $x$ direction and in the $y$ direction, for both the uncontrolled and the controlled situations. Finally, the interstory drift between the eighth and the seventh floor in the $x$ direction is depicted in Figure 7. It is observed from these Figures that the controlled response quantities can be effectively reduced compared with the uncontrolled case.

It may be illustrative to recall now the assumption made in Section II-A that the movement of the building structure is close to a rigid solid. According to this, the function $\delta(t)=c_{1} \dot{r}_{1}+k_{1} r_{1}$, which in equation 2 describes the effect (shear force) of the first floor on the base of the structure, was approximated to be zero as compared to the function $\Delta(z, t)=-m_{0} \ddot{x}_{g}-(1-\alpha) D K z$. Figure 8 plots the time histories of both functions for the actively controlled system. It is observed that $\delta(t)$ is significantly close to zero, so that the approximation assumption made in the design of the control law seems reasonable.

\section{CONCLUDING REMARKS}

Active, passive and semi-active control have been extensively considered to improve the protection of base-isolated structures against earthquakes. In this paper, a new strategy

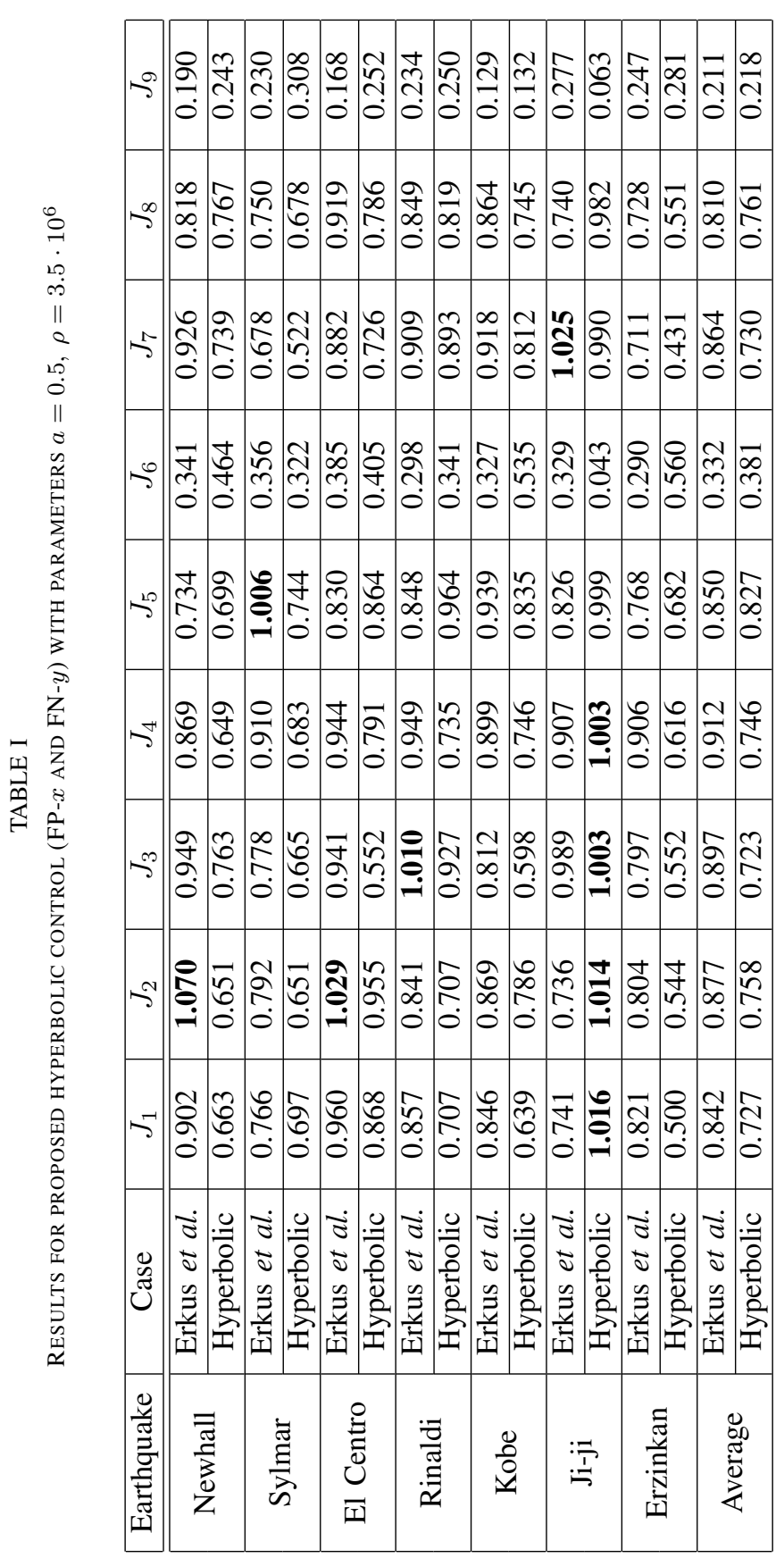




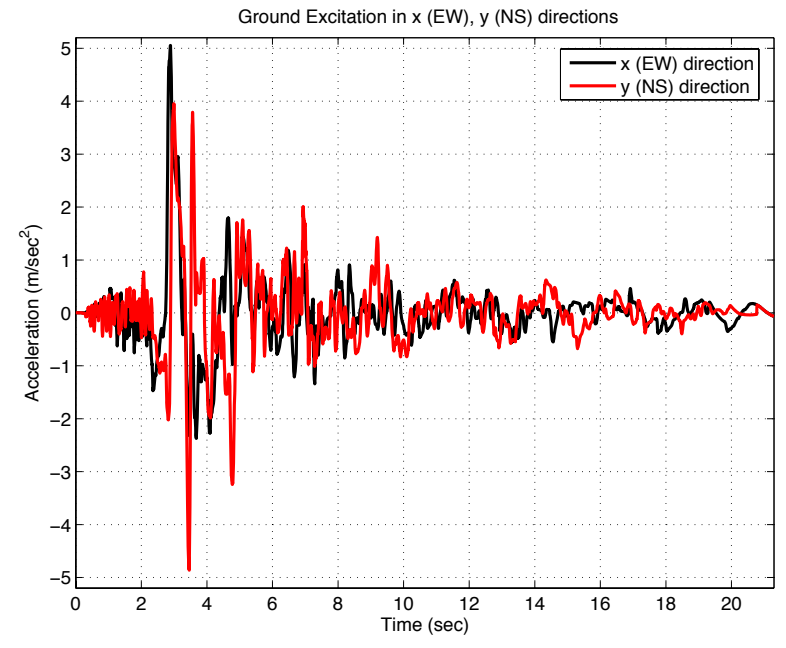

Fig. 4. 1992 Erzinkan earthquake, ground acceleration.
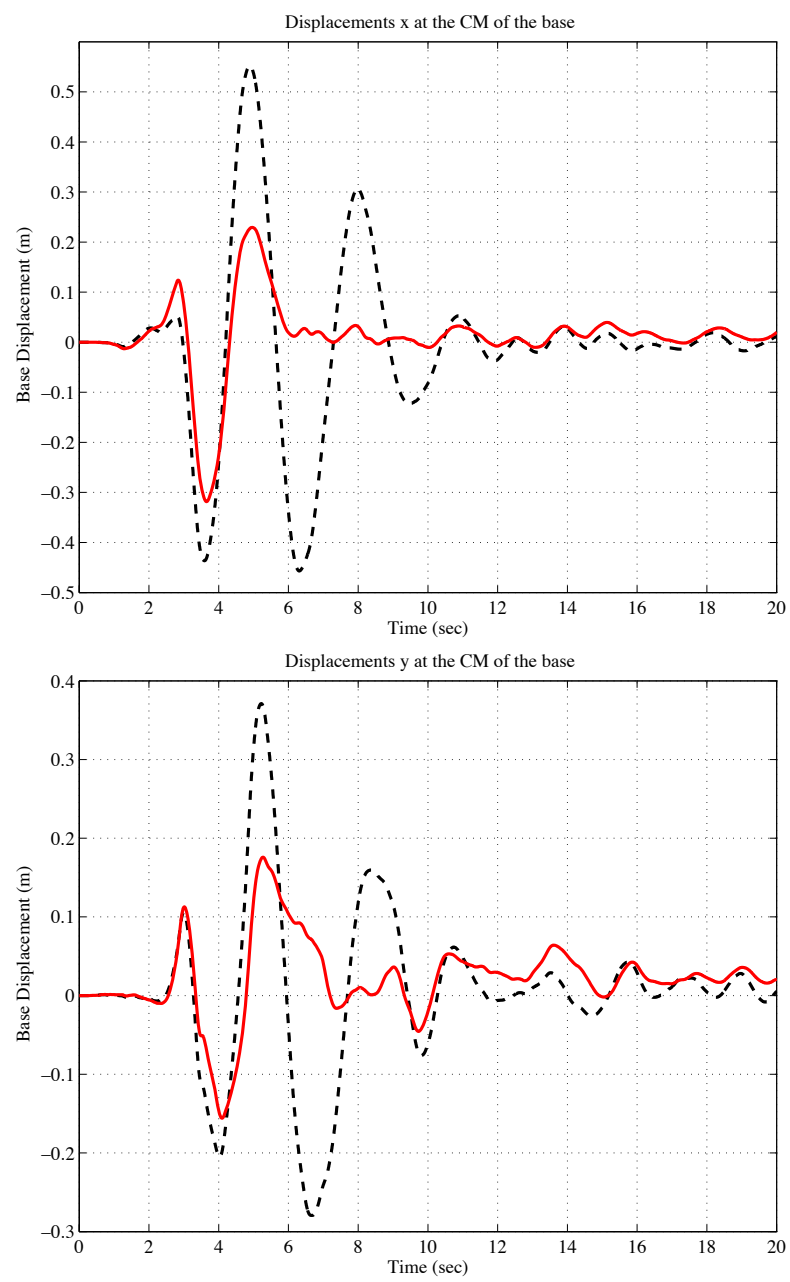

Fig. 5. Time-history of response of the isolated building under Erzinkan excitation. Displacement of the center of the mass of the base in the $x$ direction (up) and in the $y$ direction (down), for both the uncontrolled (dashed) and the controlled (solid) situations.

to apply control forces to the base of an isolated structure has
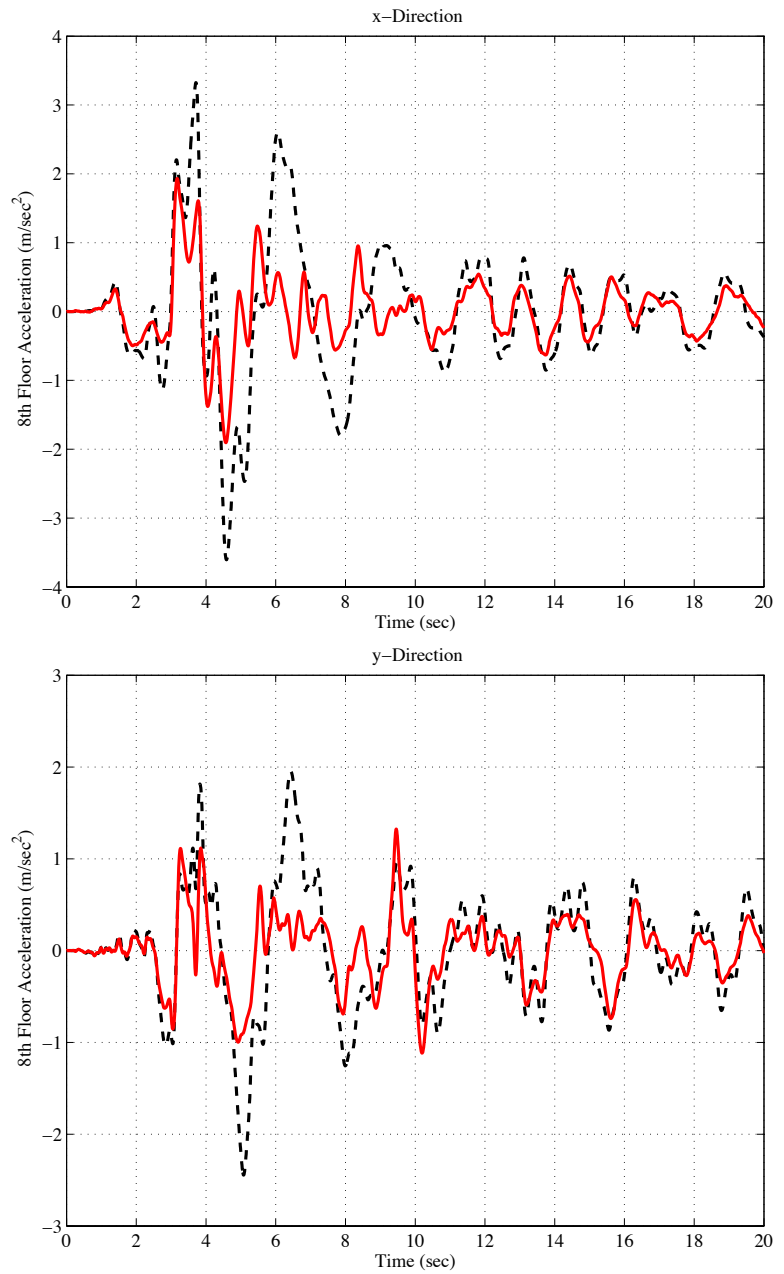

Fig. 6. Time-history of response of the isolated building under Erzinkan excitation. Absolute acceleration of the eighth floor in the $x$ direction (up) and in the $y$ direction (down), for both the uncontrolled (dashed) and the controlled (solid) situations.

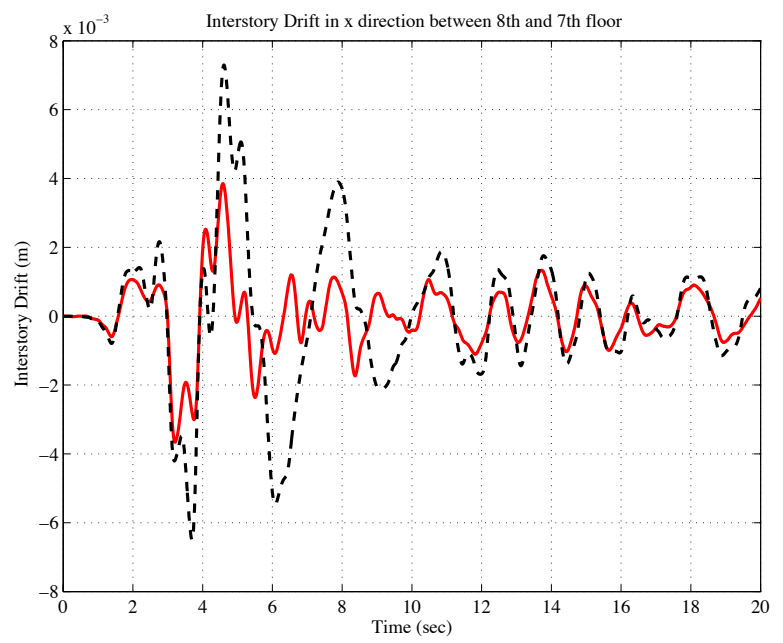

Fig. 7. Time-history of the isolated building under Erzinkan excitation. Interstory drift between eighth and seventh floor in the $x$ direction, for both the uncontrolled (dashed) and the controlled (solid) situations. 

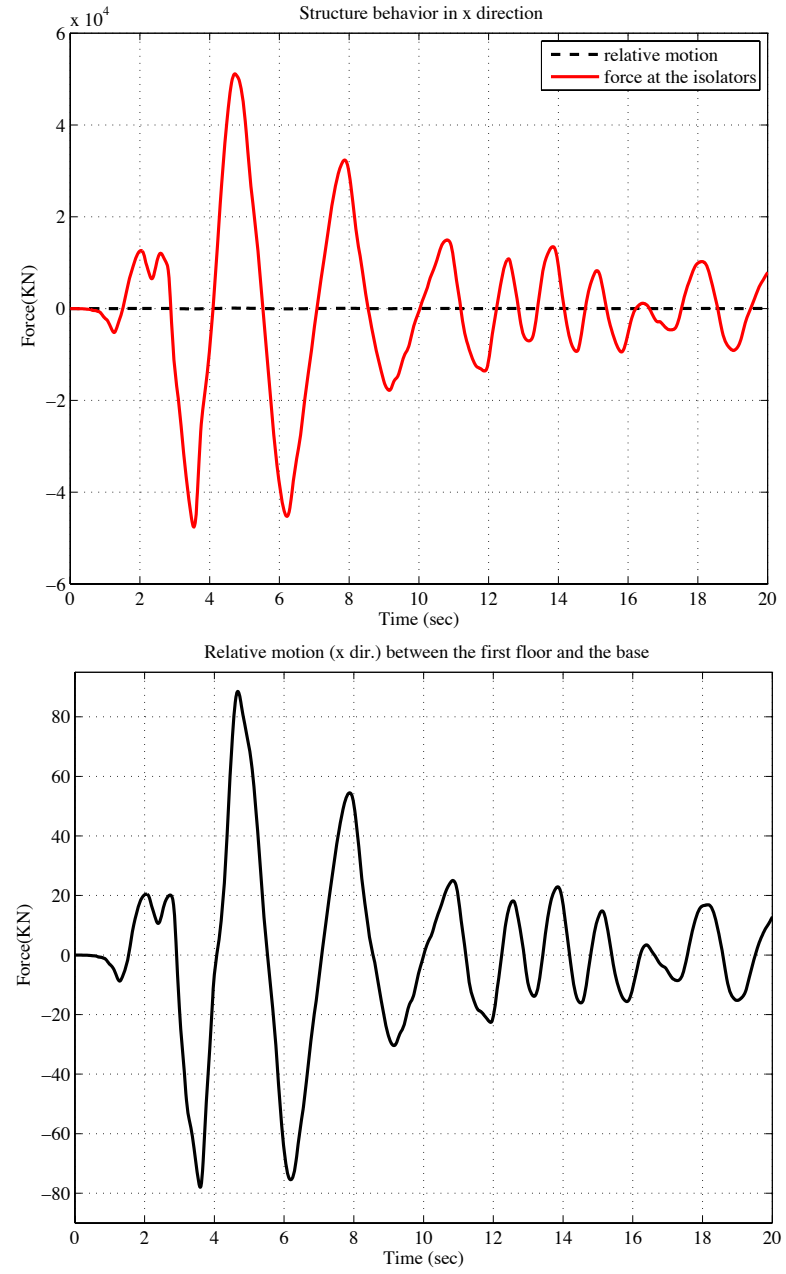

Fig. 8. Time histories of the force functions $\delta(t)=c_{1} \dot{r}_{1}+k_{1} r_{1}$ (dashed, up and down) and $\Delta(z, t)=-m_{0} \ddot{x}_{g}-(1-\alpha) D K z$ (solid, up) for the actively controlled system, in the $x$ direction under Erzinkan excitation.

been presented. The main feature of the proposed controller is its simplicity in the formulation, design and implementation. More precisely, the proposed control scheme is based on using a passive static hyperbolic function depending only on the base velocity. This function ensures energy dissipation capabilities with always bounded control force. The control has been then applied to a three-dimensional benchmark problem which is used by the structural control community as a state-of-the-art model for numerical experiments of seismic control attenuation. Since the main objective of the application has been to assess the efficiency of the concept of such stabilizing control law, it has been applied in a generic way independently of which particular actuating scheme would be available for the implementation. Finally, the performance indices have shown that the proposed hyperbolic controller behaves satisfactorily and with a reasonable control effort.

\section{ACKNOWLEDGEMENTS}

The authors would like to thank Pere M. Montserrat for his great effort in the simulation of the benchmark. This work was supported by CICYT (Spanish Ministry of Science and Innovation) through grants DPI2008-06463-C0201, DPI2008-06564-C02-02 and DPI2008-06699-C02.

\section{REFERENCES}

[1] Barbat, A., Rodellar, J., Ryan, E., and Molinares, N. (1995). Active control of nonlinear base-isolated buildings. ASCE Journal of Engineering Mechanics, 121(6):676-684.

[2] Dyke, S.J., Spencer, B.F., Sain, M.K., and Carlson J.S (1996). Modeling and control of magnetorheological dampers for seismic response reduction. Smart Materials and Structures, 5(5):565-575.

[3] Erkus, B., and Johnson, E.A. (2006). Smart base-isolated benchmark building Part III: A sample controller for bilinear isolation. Structural Control and Health Monitoring, 13(2-3):605-625.

[4] Ikhouane, F., and Dyke, S.J. (2007). Modeling and identification of a shear mode magnetorheological damper. Smart Materials and Structures, 16:605-616.

[5] Ikhouane, F., Mañosa, V., and Rodellar, J. (2005). Adaptive control of a hysteretic structural system. Automatica, 41(2):225-231.

[6] Ikhouane, F., and Rodellar, J. (2005). On the hysteretic BoucWen model. Part I: Forced limit cycle characterization. Nonlinear Dynamics, 42(1):63-78.

[7] Ikhouane, F., and Rodellar, J. (2007). Systems with Hysteresis: Analysis, Identification and Control Using the Bouc-Wen Model. John Wiley \& Sons, Inc.

[8] Inaudi, J., López-Almansa, F., Kelly, J.M., and Rodellar, J. (1992). Predictive control of base isolated structures. Earthquake Engineering and Structural Dynamics, 21(6):471-482.

[9] Irschik, H., Schlacher, K., and Kugi, A. (1998). Control of earthquake excited nonlinear structures using Lyapunov's theory. Computers and Structures, 67:83-90.

[10] Kelly, J., Leitmann, G. and Soldatos, A. (1987). Robust control of base-isolated structuresunderearthquakeexci-tation. Journal of Optimization Theory and Applications, 53(2):159-180.

[11] Jansen, L., and Dyke, S. (2000). Semiactive control strategies for MR dampers: comparative study. ASCE Journal of Engineering Mechanics, 126(8):795-803.

[12] Luo, N., Rodellar, J., Vehí, J., and De la Sen, M. (2001). Composite semiactive control of a class of seismically excited structures. Journal of The Franklin Institute, 338:225-240.

[13] Narasimhan, S., Nagarajaiah, S., Johnson, E.A., and Gavin, H.P (2006). Smart base-isolated benchmark building. Part I: problem definition. Structural Control and Health Monitoring, 13(2-3):573588 .

[14] Narasimhan, S., Nagarajaiah, S., and Johnson, E.A. (2008). Smart base-isolated benchmark building. Part IV: phase II sample controllers for nonlinear isolation systems. Structural Control and Health Monitoring, in print.

[15] Nagarajaiah, S., and Narasimhan, S. (2006). Smart base-isolated benchmark building. Part II: phase I sample controllers for linear isolation systems. Structural Control and Health Monitoring, 13(23):589-604

[16] Ohtori, Y., Christenson, R.E., Spencer, B.F., and Dyke, S.J. (2004) Benchmark problems in seismically excited nonlinear buildings. Journal of Engineering Mechanics - Proceedings of the ASCE, 130(4):366385.

[17] Pozo, F., Ikhouane, F., and Rodellar, J. (2006). Adaptive backstepping control of hysteretic base-isolated structures. Journal of Vibration and Control, 12(4):373-394.

[18] Pozo, F., Montserrat, P.M., Rodellar, J., and Acho, L. (2008). Robust active control of hysteretic base-isolated structures: Application to the benchmark smart base-isolated building. Structural Control and Health Monitoring, 15(5):720-736.

[19] Ramallo, J.C., Johnson, E.A., and Spencer, B.F. (2002). Smart base isolation systems. Journal of Engineering Mechanics - Proceedings of the ASCE, 128(10):1088-1099.

[20] Skinner, R.I., Robinson, G.H., and McVerry, G.H. (1992). An Introduction to Seismic Isolation. John Wiley \& Sons, Inc., Chichester, UK.

[21] Xu, Z., Agrawal, A.K., and Yang, J.N. (2006). Semi-active and passive control of the phase I linear base-isolated benchmark building model. Structural Control and Health Monitoring, 13(2-3):626-648. 